\title{
Gender representation in Filipino storybooks for children
}

\author{
Ma. Joahna Mante-Estacio*, Fernand Kevin Dumalay, Philip Rentillo \\ Department of English and Applied Linguistics, De La Salle University, Manila, Philippines
}

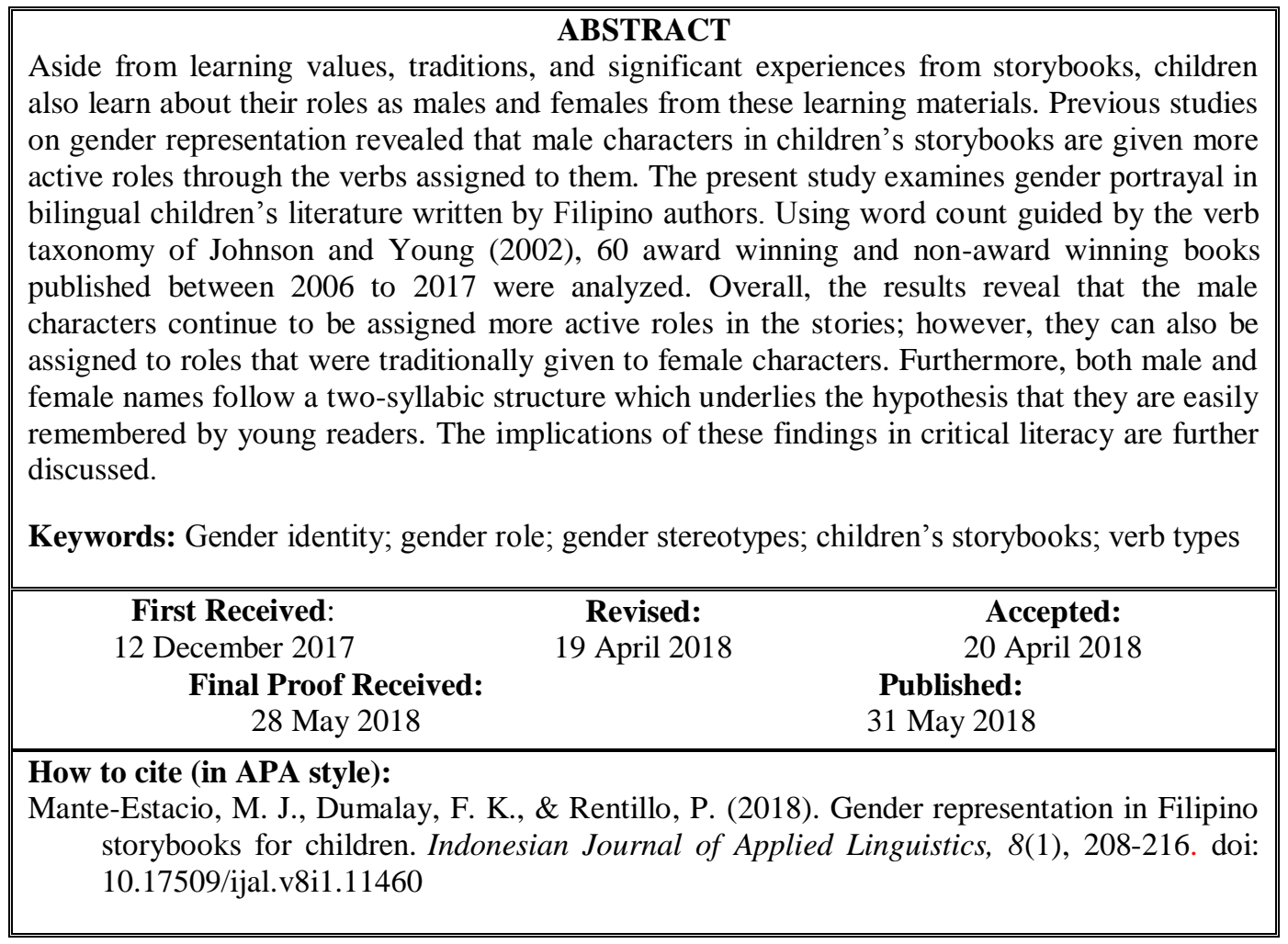

\section{INTRODUCTION}

Sumalatha (2004) argues that learning materials are among the most necessary means to mold "desirable attitudes in children" (p. 57). It is no question that various media, notably print texts (Gilbert, 1988), take this role as they are ubiquitously used in formative years and thus are considered valuable cultural resources to children. Roper and Clifton (2013) argue that there remains a disparity in representation between genders across media. Such as in television, children are targets of gender-based conditioning. This phenomenon is quite notable in advertisements which have been extensively observed to project strong gender attitudes and perceptions stereotyping towards American children (Johnson \& Young, 2002). While learning technical, social concepts have long been prioritized in education, there has been mounting necessity for gender expression and fairness as focal areas of discussion. It has then become an increasing concern as to how gender roles are imbibed within children's media such as in storybooks.
Effects of gender stereotyping on children

It is widely understood that children are generally receptive; they adopt behaviors and awareness through identification via socialization. As part of this socialization, learning materials such as print texts reinforce these paradigms based on actual human interactions. Indeed, "traditional values of the times are reflected" (Gooden \& Gooden, 2001, p. 1) in these materials. While children seek positive self-imagery, a vast amount of content intended for this audience helps sustain gender stereotypes that contribute to limiting or even downplaying their sense of identity. This can be notably seen and felt even in areas of life deemed mundane by many such as in academic areas where gender expectations are bracketed based on STEM, which are said to be more for men, versus the humanities and social sciences, which are for women (Cvencek, Meltzoff, \& Greenwald, 2011).

Effects on children's perceptions in relation to stereotypes have likewise been noted by Karniol and Gal-Disegni (2008) among Israeli first graders. It was

\footnotetext{
* Corresponding author:

Email: joahna.estacio@gmail.com
} 
seen that those exposed to gender-fair texts judged stereotypically-female activities as appropriate to both genders more than those exposed to genderstereotypical books. Such has been found in previous experiments eliciting children's perceptions towards occupational roles after exposure to books portraying gender-positive attitudes (Trepanier-Street \& Romatowski, 1999). It was also notably seen that exposure to content that break moulds help reshape children's goal ideation. This was reported by Nhundu (2007) where Zimbabwean school girls from 4th to 7th grade exposed to biographies of successful women were more likely to believe that there are no specific occupations for either men or women. These girls were also more likely to reconsider their career goals from gender-stereotypical fields to gender-atypical ones.

In a descriptive analysis by Toçi and Aliu (2013) of English textbooks used in Macedonian primary schools, it was found that gender-biased depiction of occupations and hobbies were prevalent. Males were representative of sports and science-related fields while females were consigned to fashion and hospitality. Within children's textbooks used in several Iranian language learning centers, Parham (2013) found that while female figures initiate conversations more frequently than males, they are less represented compared to their male counterparts. This extends up to secondary level in Iran according to an earlier work by Amini and Birjandi (2012). According to their examination of high school EFL textbooks, women are likewise obscured in both visual and textual depictions. Men are also "first" in most if not all contexts; the most notable is while walking which is reflective of actual Iranian social conventions where men have to walk ahead of women. Female characters are only placed in stereotypically female activities such as household chores and caretaking; they were also predominantly characterized as overemotional. Relevant patterns could be found in other secondary level materials such that in Malaysia where men outnumbered women in visibility and were frequently mentioned before females (Mukundan \& Nimehchisalem, 2008).

As children are allowed to reconstruct their ideas, Änggård (2005) did find that learning materials have indispensable effects to how children narrate their own stories. In her experiment where preschool students were asked to create their own storybooks, it was seen that boys and girls still recreate their narrations based on gender-traditional themes. These are said to be inevitably formalized due to various adult-constructed media and pop culture they absorb. Among these are storybooks, comics, television programs, movies and including toys. On the other hand, children produce innovations that veer away from strongly stereotypical images. Girls, while using princesses as protagonists, create female characters who are more active, have more agency, while male characters become secondary players. Boys still adhere to strong heroic archetypes and strikingly have no female characters, but there is an element of reconciliation with the antagonist. This denotes a view away from a typical male character framework with a violent and destructive typecast. These patterns can be seen in contexts where gender ideation whilst play is involved as attested by Wohlwend (2009) who used Engström's Activity Model Design to integrate various frameworks on social semiotics, media culture and feminist post-structural perspectives in observing child play to produce storytelling. Based on her observation and analysis of 21 kindergarteners, children reauthor established, stereotypical narratives (e.g. fairytales) to defy archetypes and produce agency and power to figures that typically lack such qualities. Children maintain to use established, saturated roles and gender hierarchies in order to extend their desire to depict autonomy and agency especially on female characters.

As traditional gender roles are forced and cemented in childhood, various research have shown that it carries on until adulthood such that choosing one's career path could be determined in accordance to how one perceives an academic field (Cheryan, Meltzoff, \& Kim, 2011; Cheryan, Plaut, Davies, \& Stoele, 2009 in Cvencek, Meltzoff, \& Greenwald, 2011). It is argued that perceptions on gender-based membership towards academic fields and pertinent professions erode one's sense of belongingness; this is a factor which deters people from pursuing a field especially girls who are expected to have equal opportunities in the sciences. Studies spanning decades have shown that elementary girls, if not performing higher, are of equal footing with boys in achievement tests in math and life sciences. These are in spite of biological studies revealing differences in spatialmathematical abilities caused by hormonal changes from pre-natal until puberty stages (see Friedman, 2007). Nonetheless, these hormonal factors are only magnified by social constructs (Halpern, 2000). While it is yet empirically uncertain where gender stereotyping in academic fields is rooted from, it was presumed to negatively affect girls' math and science test performances in later years (Cvencek et al., 2011).

Based on these notions, it can be seen that behaviors and content bring effects that steer towards and away from neutral, non-traditional behaviors and perceptions on gender roles. It is no doubt that children are quite formative and could easily adopt cultural imprints. One interesting point of inquiry therefore are materials children are constantly exposed to, and among these are storybooks. As these materials are perennial across libraries, homes and schools, it is then noteworthy to look into how much impact these leave children in their perception of gender roles that do not only affect others but likewise how they see themselves.

\section{Gender stereotyping in children's storybooks}

Parke and Clarke-Stewart (2001) claim that children tend to digest vast amounts of content with constructs helping fossilize gender bias and stereotypes. This notion has in fact been distinguished within decades of research where several studies have foreshadowed 
similar concerns specifically within storybooks (Ashton, 1983; Jennings, 1975 in Abad \& Pruden, 2013; Trepanier-Street, Romatowski \& McNair, 1990). These in fact are not only evident in texts but even in visual symbolisms. For one, images in children's picture books have long been found to convey polarizing illustrations of gender expectations. Male figures are regularly depicted as "active and domineering," while females are relegated to obscurity and are portrayed as "meek and mild" (Tsao, 2008; Turner-Bowker, 1996). This is consistent to previous findings in children's storybooks (Hamilton, Anderson, Broaddus, \& Young, 2006), and in coloring books (Fitzpatrick \& McPherson, 2010).

Stephens (1992) argues that storybooks (including picture books) usually echo what are considered as cultural norms; however, they also have tendencies to present deviant narratives. An example is from Roper and Clifton (2013) who showed that storybook illustrations depicted girls to wear appropriate attires for sports and that parents were primary agents in encouraging girls to be involved in sports or physical activities. However, peers were more likely depicted to discourage these female characters. A couple of studies have likewise looked into character association to culture material in storybook illustrations. One notable study was done by Crabb and Bielawski (1994) who identified production and household artifacts within award-winning Caldecott Medal storybooks. According to them, production artifacts symbolize work outside the home and have been traditionally associated with men; meanwhile, household artifacts refer to a domicile identity and have been frequently attached to females. Poarch and Monk-Turner (2001) conducted a follow-up study this time of non-award-winning Caldecott texts published from 1981 to 1992 . It was seen in illustrations that both genders were equal in association with leisure artifacts; however, if otherwise, men were more likely to be seen with a production artifact. Females, on the other hand, were more likely to be seen handling household objects (19\% more) compared to males. A more recent study by Crabb and Marciano (2011) looked into award-winning Caldecott storybooks within a span of nearly twenty years, or from 1990 to 2009. It was seen that traditional labor divisions pervaded. The analysis showed there was no change in female character association with production artifacts compared to males who remained to take the dominant share. This was noted as a sign of cultural lag given that these texts do not reflect the actual changes in labor patterns in the early 90's and 2000's where more American women have actually begun working outside the home.

Gender stereotyping conditions can be noted even within EFL learning environments. One comprehensive work by Mannfors (2015) analyzed English language storybooks found at the Helsinki Metropolitan Library. This study used semantic categories of lexical verb as presented by Biber, Conrad and Leech (2012 in Mannfors, 2015) and comprised of [1] activity, [2] communication, [3] mental, [4] causative, [5] occurrence, [6] existence/relationship, and [7] aspect verbs. It was found that there is higher verb association with males $(72 \%)$ or 9.3 verbs per male vs 6.5 per female. Notably, men are more depicted to use mental verbs which are highly associated with protagonists as these reveal inner thoughts. More male characters are represented in the samples $(\sim 65 \%)$ as well. Women, if portrayed, are still highly domesticated as they were more likely to represent mothers than men as fathers. While stereotypes remain, there are minimal improvements in female representation as compared to storybooks written decades prior. Women held occupations deemed traditional but slightly with more power (e.g. queens, a school headmistress).

\section{Gender stereotyping in Philippine texts}

Learning materials produced and consumed in the Philippines are no exception to these phenomenon. Java and Parcon (2016) recently assessed gender role depiction in textbooks commonly used in first grade schools in the Philippines. Their analysis ran based on Kabira and Masinjila's (1997 in Java \& Parcon, 2016) three-point gender role framework which looked into productive, reproductive and community roles. According to findings, traditional gender roles pervaded in various content. Males gravitate towards so-called productive and community roles whereas females are oriented towards the reproductive. Males are subjected to a diverse range of roles which emphasized heavy labor, while females remain represented as docile. This is parallel to findings by Quezada-Reyes (2000) who argued that patriarchal attitudes are still quite noticeable in historiography based on an analysis of select Philippine secondary school history books. It was added that women are barely mentioned in these books except as national leaders who took over after their husbands were assassinated. Men are also predominantly depicted as the defenders, while women are rendered as the defended.

Similar to what was discussed by Stephens (1992), there are certain storybooks in the Philippines that have diverged from the customary at a nuanced degree. This was observed by Torres-Yu (2011) who emphasized how current realities of Filipino families with migrant parents, whilst reinforcing gender expectations in the process, are put into children's texts. A notable template found is the overseas, widowed or single mother left responsible to be the sole breadwinner. In some cases, these female characters are compelled to take masculine professions; they are nonetheless glorified for their willingness to transcend gender norms, but at the same time for occupying the compassionate, sacrificial and nurturing niche traditionally expected from women most especially mothers.

While the aforementioned studies have looked through highly context-based analyses, preliminary findings using discourse anchored upon linguistic analysis have yielded similar results. One is by Mante (2007) who provided an initial look into verb-based gender representation among 30 Filipino storybooks. Using Johnson and Young's (2002) verb classification, 
she found that male characters were slightly more associated with agency and control verbs. On the other hand, females were more associated with feeling and nurturing verbs. This corroborates Oden's (2005) claim that women are likelier to be depicted as "emotional and sensitive" (p. 17).

\section{The present study}

There has been a considerable, increasing amount of literature on gender expression and stereotyping among children materials and their effects on their audience. However, many studies have focused on Western and/or American settings. Fully understanding issues of identity and equality within educational and popular media is crucial as societies move forward to a more inclusive, equalizing direction. There is hence a clear need to open an area of scrutiny focused on Filipino schoolchildren who are exposed to a different set of materials both in terms of content and context as compared to their counterparts who have always been the primary subjects of study. As a first step in achieving this, this paper attempts to expand upon previous work that focused on verb type occurrences in relation to gender representation in children's storybooks. This paper identified current trends in gender role expression among Filipino children's storybooks through verb types based on Johnson and Young's (2002) framework.

Five (5) verb types were identified based on function. These are [a] action, [b] agency/control, [c] destruction, [d] feeling/nurturing, and [e] limited verbs. Action verbs signify active movement and transfer from one location to another as in:

Si Juan ay kumain ng manok. Juan ate chicken.

Agency/control verbs refer to active control over people (e.g. imperatives, fulfilled requests) or objects:

Pinagsabihan ni nanay si Rita.

Mother scolded Rita.

Destruction verbs are used for change of state (e.g. entropy, damage) or causality of deterioration of a person or object (e.g. death):

Binasag ng bata ang alkansya.

The child broke the piggy bank.

Sumakabilangbuhay ang kaniyang ama.

Her father passed away.

Feeling/nurturing verbs on the other hand refer to expression of care or emotions such as:

Iniyakan ni Pablo si Pepita.

Pablo cried for Pepita.
Lastly, limited verbs convey movement similar to action verbs but with restricted degree:

Kumakaway ang tiyo.

The uncle is waving.

To further expand on the aforementioned verb taxonomy, the present researchers included negative verbs as a sixth verb category. This was based on the surface grammatical feature of the Tagalog verb negator hindi (and variant 'di), as in:

\section{Hindi naglaro ang bata.}

The child did not play.

Such occurrence of verb type suggests limitation of action or agency. This likewise provides another layer of scrutiny in characterizing gender representation through verbs in Filipino children's storybooks, which were discounted in Johnson and Young's (2002) and Mannfors' (2015) studies.

Actor-receiver dynamics as signified in verbs across genders and verb types were also considered a variable in describing gender role portrayal. This was inspired by Lysén's (2009) analysis of English verbs based on actor-receiver relationship in accordance to transitivity and dynamism. The former describes that transitive verbs create a stronger image for the actor as they signify that an agent affects a patient as compared to intransitive verbs which only affect the actor. The latter, based on the Functional Grammar Theory, describes that stative verbs merely signify expression of emotions and feelings, whereas dynamic verbs translate to more concrete actions. According to Lysén's analysis of a Swedish secondary school English book entitled Blueprint A, male characters tend to use more dynamic and transitive verbs as compared to women who use more stative and intransitive verbs. This pattern can was used in anticipation of results from the data in this study.

Oden (2005 in Mante, 2007) in his paper presented a framework which used name length based on syllabic structure to further shed light on finer details of gender representation. In relation to the connection between syllabic structure and memory retention, longer syllables rendered decreased serial recall (Lovatt, Avons, \& Masterson, 2000). According to Oden more females were named, but there was a higher frequency of males being given one-syllable names. This creates an impression that male characters might be more memorable than the females. It can likewise be seen that female characters are still more disadvantaged with regard to naming. Oden argues that names relate to personal significance, and males are typically given shorter names compared to females. Short names also "create the impression of quick, attentive, and straightforward person traditionally associated with males" (p. 19).

Based on the discussion presented above, it is suggested that there is a need to provide a more in-depth 
look into gender representation in children's storybooks from a discourse perspective. This was achieved in this study by investigating verb types in relation to male and female characters. In addition, character name length in accordance to character gender was also considered to be another layer of inquiry. The present study is expected to answer three research questions using sixty (60) Philippine-published children's storybooks in Filipino.

1. How is gender represented based on verb types commonly associated with males and females in some children's storybooks?

2. How is gender represented based on actorreceiver roles commonly associated with males and females in some children's storybooks?

3. How is gender represented based on the difference between male and female name syllable structures?

\section{METHOD}

As mentioned, reading materials may have an impact on how young children perceive and form their individual identities, and values systems. It is vital to provide an insight as to whether the attribution of certain verb elements to a specific gender is a collective conscious decision of writers of this genre. Hence, the aim of this exploratory, a descriptive study is to investigate how gender is portrayed and whether the story books designed for children (7-12 years old) have signs of sexism in actions and dialogues among the characters.

\section{Corpus}

Sixty (60) Filipino-English bilingual children's storybooks were used as the basis of the corpus. These storybooks were originally written in Filipino by Filipino authors, and were produced by major publishing houses in the country. The collection has both award winning and non-award winning stories for seven to twelve-year-old children which were more recently published, around 2006 to 2017.

\section{Procedures}

This study sought to establish whether there is gender bias in some children's story books by analyzing the conversations and actions of the characters, and also the names and titles given to them. The roles of the characters as regards being the actors or the receivers of the verbs are also examined. Illustrations and other graphic elements are not included in the analysis but are used as bases in identifying and interpreting ambiguous gender representations.

The 60 storybooks were distributed among the researchers, with each book read and analyzed for classification of Filipino verb elements by two researchers. After creating individual tallies with initial classification of verbs, the researchers would meet to compare and to validate their interpretations. The analysis was based on the taxonomy proposed by Johnson and Young (2002) which suggests that verb elements may be classified into action (verb elements with executors causing physical movement or motion), limited (state of being verb elements or those involving minimal physical movement), destruction (verb elements causing devastation or harm), agency and control (verb elements demonstrating power relations someone being controlled by another, or powerful person causing drastic change), feeling and nurturing (verb elements displaying affection, and emotions). Another emerging category, negative verbs, was included in the analysis as this became a recurring verb type in most of the sample books. The verb elements found in the conversations (including self-talk) and descriptive passages are manually counted and listed per book using Excel file. It was opted to exclude conditional verbs and modals in Filipino as they could not be categorized. Inanimate characters who were anthropomorphized in the stories were also included in the analysis as long as they were assigned genders. The inter-raters also identified certain verbs found in the books which were ambiguous such as the word tago ('to hide'), which can be classified as either a limited or action verb depending on the context. They also further discussed to determine its most appropriate classification (e.g. verbs with physical movement from one point to another were classified as action). The inter-rater reliability for all the meetings ranged from 90 to $95 \%$ which was beyond the usual $70 \%$ acceptability rating.

To answer the first research question, How is gender represented based on verb types commonly associated with males and females in some children's storybooks, a final list of Filipino verbs with their corresponding classifications was produced. The researchers computed for the total number of verbs used according to types per gender, and made interpretations based on the results.

To answer the second research question, How is gender represented based on actor-receiver roles commonly associated with males and females in some children's storybooks, the identified verbs were further analysed according to whether the particular gender was the receiver or the doer of the action. The roles portrayed were manually tallied and a final sheet was prepared using an Excel file.

Finally, to answer the third research question, How is gender represented based on the difference between male and female name syllable structures, the names including the titles were tabulated according to gender. The number of syllables per name for both genders was counted. The presumption is that longer names (having more syllables) may signify importance and prestige (Oelkers, 2002 in Oden, 2005). The data with computed percentages were then consolidated in one file and rechecked. A final tally of verbs labelled accordingly and names with total number of syllables was produced. The results were then interpreted vis-à-vis the findings of other literatures. Finally, conclusions were 
formulated as regards gender portrayal in the sampled children's story books, and their social and pedagogical implications were elaborated.

\section{Data analysis}

This study used a quantitative approach in determining gender representation in Filipino children's storybooks. Primarily verb occurrences in association with male and female characters were analyzed. As part of the descriptive statistics, frequency and percentage of verbs per gender across verb types and actor-receiver relationship were computed. A chi-square analysis was employed on data to test relationships between variables. This was done for verb types and gender, and verb types and roles. Another chi-square analysis was conducted on verb types and actor-receiver roles exclusively per gender. Character name lengths through syllable length were also included as an additional basis. Descriptive statistics were identified for both genders particularly on the frequency, mean and standard deviation of syllable count. A t-test was likewise was employed between the number of characters per gender and verb occurrences to further confirm whether verb frequency is linked to gender representation.

\section{RESULTS AND DISCUSSION}

Based on the corpus collected and analyzed, the following are the results aimed to answer the questions of this study.

1. How is gender represented based on verb types commonly associated with males and females in some children's storybooks?

Table 1 presents the number of verbs associated with the male and female characters in the different verb categories. Out of the 3,185 verbs, $85 \%$ are associated with the male characters. This shows that the female and male characters are not equally represented in the stories for children in terms of the number of verbs associated with them. The male characters dominated all verb types from as high as $90 \%$ of the Action Verbs to the $71 \%$ of the verbs in the Agency/Control category. A paired-samples t-test was conducted to compare total male and total female verb frequencies. It is seen that there is significant difference in total verb frequencies between genders; $\mathrm{t}=0.106684787, \mathrm{p}=0.05$.
Table 1. Total frequency of verbs per gender across verb categories

\begin{tabular}{lrr}
\hline Verb category & Male $\boldsymbol{f}$ & Female $\boldsymbol{f}$ \\
\hline Action & 345 & 37 \\
& $(90.31 \%)$ & $(9.69 \%)$ \\
Agency/control & 224 & 92 \\
& $(71.89 \%)$ & $(28.11 \%)$ \\
Destruction & 31 & 10 \\
& $(76.61 \%)$ & $(23.39 \%)$ \\
Feeling/nurturing & 347 & 62 \\
& $(85.84 \%)$ & $(14.16 \%)$ \\
Limited & 1529 & 228 \\
& $(87.02 \%)$ & $(12.98 \%)$ \\
Negative & 238 & 42 \\
& $(85 \%)$ & $(15 \%)$ \\
Category Total & 2714 & 471 \\
\hline
\end{tabular}

The verbs assigned to the female characters are mostly in the Limited Action category. These results are similar to the previous study by Oden (2005) which reported male characters to have more representation in stories for children. It should be noted though that since the male characters in the current study also led in the Feeling/Nurturing verb category, it may be considered as a positive result since verbs in this category reflect emotions and affection which were associated more with females in previous studies (Oden, 2005). Another variation from previous results is the big number of Agency/Control verbs to the female characters; this implies that these characters are described as energetic and powerful.

2. How is gender represented based on actorreceiver roles commonly associated with males and females in some children's storybooks?

As seen in Table 2, sixty seven percent $(67 \%)$ of the verbs show both female and male characters as actors/doers. They signify the agents in the stories or those who perform active actions such as moving, working, dancing and playing. However, there is a conspicuous imbalance in between genders when comparing overall frequency of actor roles between male and female characters whereby $84.85 \%$ of the time is assigned to the former. In applying a paired-samples t-test on male and female actor samples, it was shown that there is significant difference between two groups; $\mathrm{t}$ $=0.112657685, \mathrm{p}=0.05$. A similar pattern was observed when comparing receiver roles cross-gender; $\mathrm{t}$ $=0.100033595, \mathrm{p}=0.05$.

Table 2. Total frequency of verbs per gender across actor-receiver roles

\begin{tabular}{llccccccc}
\hline \multicolumn{2}{c}{ Character role } & Action & $\begin{array}{c}\text { Agency/ } \\
\text { control }\end{array}$ & Destruction & $\begin{array}{c}\text { Feeling/ } \\
\text { nurturing }\end{array}$ & Limited & Negative & TOTAL \\
\hline Male & Actor & 262 & 127 & 25 & 210 & 1007 & 167 & 1798 \\
& Receiver & 83 & 97 & 6 & 137 & 522 & 71 & 916 \\
Female & Actor & 22 & 71 & 8 & 47 & 141 & 32 & 321 \\
& Receiver & 15 & 21 & 2 & 15 & 87 & 10 & 150 \\
\hline
\end{tabular}

Looking deeper into the results, it can be noticed that even Nurturing/Feeling verbs are used actively; moreover, even in this category which is traditionally dominated by female characters, the male characters in the stories are given more active roles. On some positive note, only 33 verbs in the actor role have been assigned 
to the Destruction Verb category implying that the stories in general do not present the characters as doing harm to themselves or other people.

One possible reason why both the female and male characters were assigned the actor role more is due to the usual style of authors in narrating stories where the active voice is more commonly used than the passive voice. Sentence like Hinalikan ni Ben ang Nanay niya (Ben kissed his mother) is more common than a sentence like Ang Nanay ay hinalikan ng anak niya (The mother was kissed by her child).

3. How is gender represented based on the difference between male and female name syllable structures?

Table 3 shows the names assigned to the children characters in the stories. Both male and female characters are assigned with short, two-syllable names. However, it should be noted that all 43 two-syllable male names represent $32.82 \%$ of all 131 mentioned character names across genders as compared to female counterparts which only comprise $18.32 \%$ of the total name count. It can also be seen that generally more names are assigned to male characters (58.78\%), and thus are more identified in the stories. Running a pairedsamples t-test on male and female character names, which correspond to all named characters, there is indeed a significant gap between males and females in terms of naming; $\mathrm{t}=0.535878323 ; \mathrm{p}=0.05$. This result is similar to what was reported by Oden (2005) and Freebody and Baker (1987) where more male names are mentioned in the stories (58\% and 59\%, respectively). Oelkers (2002 in Oden, 2005) explains that traditionally, "long names are sound-dominated, soft, and (create) pleasant impression" while "short names create the impression of quick, attentive, and straightforward person traditionally associated with males" (p.19), and the results of the current study seem to show the same scenario.

Table 3. Character name assignment

\begin{tabular}{lcc}
\hline \multicolumn{1}{c}{ Name type } & Male $\boldsymbol{f}$ & Female $\boldsymbol{f}$ \\
\hline One-syllable names & 3 & 2 \\
Two-syllable names & 43 & 24 \\
Three-syllable names & 7 & 6 \\
Four-syllable names & 1 & 1 \\
Five-syllable names & -- & 1 \\
Names with titles & 21 & 20 \\
Full names & 2 & -- \\
Total & 77 & 54 \\
\hline
\end{tabular}

A slight improvement of sorts that is worthy to mention is that in terms of character named with titles, the male and female characters have almost the same number (21 and 20 respectively). Most of titles attached to character names are honorifics such as tatay ('father'), nanay ('mother'), ate ('older sister'), kuya ('older brother'). As a key feature signifying social dynamics within language, this highlights one of the many social modes of how Filipinos express respect within their cultural paradigm. As part of storybook content, this emphasizes specific value cues, articulated to both genders, within Filipino culture that are almost indispensably imparted to children.

\section{CONCLUSION AND IMPLICATIONS}

In general, the results of the analysis of 60 children's story books revealed unequal portrayal as regards the use of verb elements and naming system. Male characters consistently dominate all verb types. It is seen that limited verb type is the most commonly utilized category for both male and female characters contrary to the traditional belief that males would use more action verbs highlighting their physical strength and vigor. Moreover, most characters exhibit nonaggressive/destructive behavior towards other characters and their actions are relatively appropriate for young children.

Gender stereotypes like males being authoritative and dominating, and females having submissive attitude are not reinforced but rather subtly being revised as feeling/nurturing verb elements usually attributed to female gender are used by male characters, and verbs showing agency and control (power and status) are prominent in discourses referring to female characters. This creates an impression that one cannot assume certain personality traits and behavior to a specific gender.

The analysis also showed that characters are often doers of the verbs instead of assuming the receiver role, which supports that idea that active voice syntactic construction is commonly used by story book writers. In relation to the naming system, both genders have names which are composed usually of two syllables. Both female and male characters are equally given importance as regards attributing appropriate titles which show respect and courtesy such as $\operatorname{ali}(n g), M r$, nanay, tatay, ate, and kuya. However, it is important to note that male characters still dominate most of the stories examined showing gender inequality and bias.

The significance of these results is related to the fact that stereotypes, prejudices, and inappropriate perceptions about genders may be based on the message of literary materials children read at home and in school. An effective discussion of these roles and events in a story is the core of critical literacy which must be practiced to avoid adverse implications to the perceptions of children toward sexes. A critical evaluation of these stories of both parents and educators is an imperative since young learners may use these gender portrayals as models in forming individual identities. Should certain stereotypes be highly reinforced by some texts, especially in academic institutions where some story books are prescribed, it is an important obligation that the teacher clarifies misconception and reiterates gender equality. This intervention will help learners eventually develop their critical thinking skills which would enable to them to reach acceptable judgments independently. 
It is desirable that writers and publishers concur to create stories which portray men and women with equal potentials and have the freedom to present themselves flexibly without conforming to any social expectations. The idea that males and females are mostly alike as regards their cognitive capacity, must be observed by authors in order to help parents and educators deliver appropriate content to students. It is only fitting to depict males who are not afraid to express their emotions and females who are strong, and intelligent leaders. By doing so, children become aware of their potentials and empower them to visualize themselves getting multiple opportunities in the future. Therefore, it is vital for writers of children literature to be more sensitive in conceptualizing stories since, indeed, they have the power to create this possibility for the young learners.

Revisiting the analysis, one element that affected the approach in parsing the verbs from the corpus relates with issues regarding noun-verb distinction in Tagalog which has been in fact a decades-long debate (Bloomfield, 1917; Gil, 1993; Himmelmann, 1991 in Booij, Lehmann \& Mugdan, 2000; Jacobsen, 1979; Otanes \& Schachter, 1972). As what can be suggested from analyses accumulated so far — nonetheless still a great area of contention up to this day - Booij, Lehmann and Mugdan (2000) argue that Tagalog may have distinct classes for nouns and verbs as far as morphology is concerned. However at the syntactic level it has a so-called equational structure within clauses where the topic and the predicate are analytically balanced against one another. This implies that Tagalog word classes, as in the nature among Philippine languages, have no scope for grammatical relations like in other languages, and are semantically affected by the inflectional system of the language as it interplays within the broader syntax. Such reality provides a caution parallel to any research attempting to integrate grammatical aspects of the language into its framework. As such, this complexity was observed in this study.

\section{REFERENCES}

Abad, C., \& Pruden, S. M. (2013). Do storybooks really break children's gender stereotypes? Frontiers in Psychology, 4, 986. doi: 10.3389/fpsyg.2013.00986

Amini, M., \& Birjandi, P. (2012). Gender bias in the Iranian high school EFL textbooks. English Language Teaching, 5(2), 134-147. doi: 10.5539/elt.v5n2p134

Änggård, E. (2005). Barbie princesses and dinosaur dragons: Narration as a way of doing gender. Gender and Education, 17(5), 539-553. doi: 10.1080/09540250500192777

Ashton, E. (1983). Measures of play behavior: The influence of sex-role stereotyped children's books. Sex Roles, 9(1), 43-47.
Bloomfield, L. (1917). Tagalog Texts with Grammatical Analysis: List of formations and glossary (Vol. 3, No. 2-4). Champaign, IL: University of Illinois.

Booij, G. E., Lehmann, C., \& Mugdan, J. (Eds.) (2000). Morphologie: Ein Internationales Handbuch zur Flexion und Wortbildung, Volume 1. Berlin: Walter de Gruyter.

Crabb, P. B., \& Bielawski, D. (1994). The social representation of material culture and gender in children's books. Sex Roles, 30, 69-79.

Crabb, P. B., \& Marciano, D. L. (2011). Representations of material culture and gender in award-winning children's books: A 20-year follow-up. Journal of Research in Childhood Education, 25, 390-398. doi: 10.1080/02568543.2011.605209

Cheryan, S., Meltzoff, A. N., \& Kim, S. (2011). Classrooms matter: The design of virtual classrooms influences gender disparities in computer science classes. Computers \& Education, 57(2), 1825-1835.

Cvencek, D., Meltzoff, A. N., \& Greenwald, A. G. (2011). Math-gender stereotypes in elementary school children. Child Development, 82(3), 766779. doi: 10.1111/j.1467-8624.2010.01529.x

Freebody, P., \& Baker, C. (1987). The construction and operation of gender in children's first school books'. Women, Language and Society in Australia and New Zealand. Sydney: Australian Professional Publications, 80-107.

Fitzpatrick, M. J., \& McPherson, B. J. (2010). Coloring within the lines: Gender stereotypes in contemporary coloring books. Sex Roles, 62, 127 137.

Friedman, C. K. (2007). The socialization of gender. In J. E. Grusec \& P. D. Hastings (Eds.), Handbook of Socialization: Theory and Research (pp. 561-587). New York, NY: Guilford Publications.

Gil, D. (1993). Tagalog semantics. Annual Meeting of the Berkeley Linguistics Society, 19(1), 390-403.

Gilbert, P. (1988). Stoning the romance: Girls as resistant readers and writers. Curriculum Perspectives, 8(2), 13-18.

Gooden, A. M., \& Gooden, M. A. (2001). Gender representation in notable children's picture books: 1995-1999. Sex roles, 45(1-2), 89-101.

Halpern, D. E. (2000). Sex Differences in Cognitive Abilities (3rd ed.). Mahwah, NJ: Lawrence Erlbaum Associates.

Hamilton, M. C., Anderson, D., Broaddus, M., \& Young, K. (2006). Gender stereotyping and underrepresentation of female characters in 200 popular children's picture books: A twenty-first century update. Sex Roles, 55, 757-765.

Jacobsen, W. (1979). Noun and verb in Nootkan. In The Victoria conference on northwestern languages (pp. 83-155). British Columbia Provincial Museum Victoria, BC.

Java, J. R. B., \& Parcon, C. R. F. (2016). Gendered illustrations in Philippine textbooks. Asia-Pacific Higher Education Research Journal, 3(1), 34-51. 
Johnson, F. L., \& Young, K. (2002). Gendered voice in children's television advertising. Critical Studies in Media Communication, 19(4), 461-480.

Karniol, R., \& Gal-Disegni, M. (2008). The impact of gender-fair versus gender-stereotypical basal readers on 1st-grade children's gender stereotypes: A natural experiment. Journal of Research on Childhood Education, 23(4), 411-420. doi: 10.1080/02568540909594670

Lovatt, P., Avons, S. E., \& Masterson, J. (2000). The word-length effect and disyllabic words. The Quarterly Journal of Experimental Psychology: Section A, 53(1), 1-22.

Lysén, U. F. (2009). Verb dynamics: A study of gender roles in Blueprint A [Published undergraduate thesis]. Gävle, Sweden: University of Gävle.

Mante, M. J. (2007). Gender portrayal in Filipino reading books for children. Reading Association of the Philippines Journal, 30, 32-40.

Mannfors, E. (2015). Pretty princesses and brave knights: The presentation of gender in children's picture books (Master's thesis). Helsinki: University of Helsinki.

Mukundan, J., \& Nimehchisalem, V. (2008). Gender representation in Malaysian secondary school English learning textbooks. Indonesian Journal of English Learning Teaching, 25, 115-136.

Nhundu, T. J. (2007). Mitigating gender-typed occupational preferences of Zimbabwean primary school children: the use of biographical sketches and portrayals of female role models. Sex Role, 56, 639-649. doi: 10.1007/s11199-007-9204-6

Oden, P. (2005). Gender in English Teaching Books. Luleå, Sweden: Luleå University of Technology.

Parham, F. (2013). Gender representation in children's EFL textbooks. Theory and Practice in Language Studies, 3(9), 1674-1679. doi:10.4304/tpls.3.9.1674-1679

Parke, R. D., \& Clarke-Stewart, A. (2011). Social Development. Hoboken, NJ: J. Wiley \& Sons.

Poarch, R., \& Monk-Turner, E. (2001). Gender roles in children's literature: a review of non-awardwinning "easy-to-read" books. Journal of research in childhood education, 16(1), 70-76.

Quezada-Reyes, Z. (2000). An agenda for gender-fair education. Human Rights Education in Asian
Schools, 3, 89-94. Retrieved from http://www.hurights.or.jp/pub/hreas/3/11 reyes.pdf

Roper, E. A., \& Clifton, A. M. (2013). The representation of physically active girls in children's picture books. Research Quarterly for Exercise and Sport, 84, 147-156. doi: 10.1080/02701367.2013.784844

Otanes, F. T., \& Schachter, P. (1972). Tagalog reference grammar. Berkeley, CA: University of California Press.

Stephens, J. (1992). Language and Ideology in Children's Fiction. New York, NY: Longman.

Sumalatha, K. (2004). Sex bias in secondary school social textbooks: A case study in India. American Journal of Applied Sciences, 1(1), 62-63.

Toçi, A., \& Aliu, M. (2013). Gender stereotypes in current children's English books used in elementary schools in the Republic of Macedonia. American International Journal of Contemporary Research, 3(12), 32-38.

Torres-Yu, R. (2011). Childhood and family in contemporary children's fiction: Resilience, agency, and emergence of new gender norm. Kritika Kultura, 16, 44-64.

Trepanier-Street, M. L., \& Romatowski, J. A. (1999). The influence of children's literature on gender role perceptions: A reexamination. Early Childhood Educational Journal, 26(3), 155-159. doi: 10.1023/A:1022977317864

Trepanier-Street, M. L., Romatowski, J. A., \& McNair, S. (1990). Development of story characters in gender-stereotypic and-nonstereotypic occupational roles. The Journal of Early Adolescence, 10(4), 496-510.

Tsao, Y. L. (2008). Gender issues in young children's literature. Reading Improvement, 45(3), 108-114.

Turner-Bowker, D. M. (1996). Gender stereotyped descriptors in children's picture books: Does "curious Jane" exist in the literature? Sex Roles, 35(7), 461-488. doi: 10.1007/BF01544132

Wohlwend, K. E. (2009). Damsels in discourse: Girls consuming and producing identity texts through Disney Princess play. Reading Research Quarterly, 44(1), 57-83. doi: 10.1598/RRQ.44.1.3. 